\title{
AC 2012-3326: INNOVATIVE CURRICULUM FOR ENGINEERING IN HIGH SCHOOL (ICE-HS): STATUS UPDATE
}

\section{Dr. Shamsnaz Virani, Pennsylvania State University, Great Valley}

Shamsnaz S. Virani, Assistant Professor of Systems Engineering at the Pennsylvania State University, Great Valley, earned her Ph.D.in industrial and systems engineering from the University of Alabama, Huntsville. She also holds a M.S. in human factors engineering from Wright State University and a B.S. in electrical engineering from The University of Pune, India. Prior to joining Penn State, Virani worked with the Research Institute for Manufacturing and Engineering Systems at the University of Texas, El Paso. She was also a Visiting Assistant Professor at the University of Alabama, Huntsville. Virani's research interests include engineering education, empirical software quality, and cognitive perspectives of systems engineering teams. She teaches decision and risk analysis, software systems architecture, and systems integration, verification, and validation. She is a member of ASEE (American Society of Engineering Education) and IIE (Institute of Industrial Engineers).

\section{Ms. Iris B. Burnham, Da Vinci School for Science and the Arts}

Iris B. Burnham is the Founder and Superintendent of the Burnham Wood Charter School District in El Paso, Texas. The Da Vinci School serves grades 5-12 and has been designated an Innovative STEM Academy by the Texas Education Agency. Burnham 's career includes more than 30 years of teaching, designing curriculum and implementation of education programs for students of all ages including new teachers. 


\title{
Innovative Curriculum for Engineering in High School (ICE-HS)—Status Update
}

\begin{abstract}
The ICE-HS was developed to address the need to define an engineering curriculum in a charter high school. The research team reviewed several vendor prescribed curricula such as project lead the way and infinity, and digital libraries funded by NSF and ASEE such as teachengineering.org, cadrek12.org and egfi.org. The inflexibility of vendor sold curricula and lack of structure with the digital libraries posed some challenges for teaching engineering in high school. The school needed some customization of available curricula for implementing a discrete engineering course The ICE-HS was thus developed to address this need. The ICE-HS presents a step-by -step methodology for developing a four- year high school engineering curriculum framework based on backward design and systems thinking approaches. The ICE-HS is structured around two major objectives: attracting the high school students to STEM and providing a flexible engineering foundation. It does not prescribe specific modules but offers integration with the other disciplines such as language/arts and traditional science courses. The ICE-HS uses digital libraries and vendor sold curricula providing a framework that allows the school to customize its delivery for appropriate grades and levels.
\end{abstract}

The ICE-HS is currently being piloted in a charter high school, Da Vinci School for Science and the Arts. This paper presents the ICE-HS approach, syllabus of each of the courses developed using ICE-HS, and initial data indicating positive impact on student learning .

\section{Introduction}

This December, The Oregonian ${ }^{1}$ reported, "It turns out, teenagers aren't avoiding careers in engineering because they think it's geeky. They're simply unaware of what engineers do," according to a study of 1,000 teenagers commissioned by Intel and nonprofit Change the Equation. The "survey showed 63 percent of the students ages 13 to 18 have never considered the career despite having 'generally positive opinions of engineers and engineering.' The perception that engineering is difficult also played a part in the lack of job consideration."

This was further supported by VentureBeat ${ }^{2}$ “Currently, around one-third of teens can't name any potential job opportunities in engineering fields. Roughly 13 percent don't think that an engineering degree would be more likely to lead to a great job than any other major. And a full 20 percent of these teens have no concept of just how much engineering shapes the world around us."

Pre-college engineering is especially problematic in STEM education since there is no wellestablished tradition of engineering in the K-12 curriculum, or as part of teacher preparation and certification processes. The result: most K-12 teachers and administrators are ill-prepared to advise students about engineering careers, much less to introduce engineering knowledge and skills into the classroom. While there is a growing appreciation that engineering may be a positive vehicle to motivate K-12 student study of other STEM subjects ${ }^{345}$, some emerging research indicates that there are circumstances in which this position may not be entirely valid ${ }^{6}$. However, the gaps in experience with engineering in the K-12 setting make these kinds of discussions difficult to a large degree, because there is no epistemic foundation to give them 
context. Engineering in K-12 Education, a report released recently by the National Academy of Engineering ${ }^{7}$, and the National Research Council, make a number of convincing arguments for engineering as "a catalyst for a more interconnected and effective K-12 STEM education system," and recognizes that this outcome "will require significant rethinking of what STEM education can and should be".

Among the wide variety of engineering programs developed for K-12 education, such as vendor prescribed curricula; project lead the way and infinity, and digital libraries funded by NSF and ASEE; teachengineering.org, cadrek12.org and egfi.org. The inflexibility of vendor sold curricula and lack of structure with the digital libraries pose challenges for teaching engineering in high school. There is a need of not only a mechanism for customization of engineering education in high school based on their wants and needs but also a support structure to sustain and continuously improve engineering education in high school. The ICE-HS framework as applied to the Da Vinci School provided not only a mechanism of customization but also a support structure and continues improvement.

\section{The Da Vinci Case Study}

The Da Vinci School for Science \& the Arts, a designated STEM academy funded through the Texas Education Agency’s T-STEM Initiative, required help to develop an engineering curriculum and teaching methodology that would successfully interest all students in the problem solving and design thinking prevalent in all engineering fields. Da Vinci has an 80 percent minority population with 43 percent at-risk students. The engineering course developed was to be offered to all students as opposed to student self-selection and the course would be offered at least 3 hours a week. The school reviewed the vendor specific engineering curricula but found it expensive to implement for their budget. The teachers had undergone several training were familiar with egg-drop, Lego robotics and other activities to promote engineering in high school but lacked structure to introduce them as a discrete engineering course.

After several meetings, discussions with the teachers and research the authors concluded that along with the understanding by design approach to curriculum they would use a systems approach to the defining engineering in high school.

Systems engineering, as defined by International Council of Systems Engineering's (INCOSE) Systems Engineering Handbook is a profession, a process, and a perspective as illustrated by these three representative definitions.

1. Systems engineering is a discipline that concentrates on the design and application of the whole (system) as distinct from the parts. It involves looking at a problem in its entirety, taking into account all the facets and all the variables and relating the social to the technical aspect $^{8}$

2. Systems engineering is an iterative process of top-down synthesis, development, and operation of a real-world system that satisfies, in a near optimal manner, the full range of requirements for the system ${ }^{9}$

3. Systems engineering is an interdisciplinary approach and means to enable the realization of successful systems ${ }^{10 .}$

The grand challenges of 21st century are complex engineering problems requiring a systems thinking approach. The authors believe that introduction on systems engineering design process to the teachers in high school would lead to broadening their perspective on engineering. 
Students experiencing systems engineering projects in their classrooms understand the complexity of the futuristic problems and the mechanism to solve them. Furthermore, the highly engaging challenge that a systems engineering approach offers the novice by asking a student to imagine an outcome and apply all their creativity and fancy to the solution becomes an enticing and limitless project to a young mind. Once the student has envisioned their model, then the nuts and bolts of engineering are introduced to show how it might be realized. Hence- a perfect instructional hook. The engineering content for ICE-HS Framework is inspired by systems engineering discipline.

The ICE-HS Framework is designed with the adaptation of a logical instructional model that is based on the professional standard for instructional delivery, Understanding by Design (UBD). This format begins with clear objectives for student outcomes using Bloom's Taxonomy; a Motivational or Student Engagement Component; an array of delivery methodologies including team work, lecture, project-based learning and inquiry-based learning; concluding with selfreflection exercises and formative assessment of the objectives. The specific artifacts of the UBD including the mission goals, essential questions and the objectives are included in appendix. A core group of science, math and technology teachers, and the school superintendent were involved in the development of the UBD artifacts customizing the curriculum to Da Vinci school.

For example, the Framework in the 9th grade begins with Engineering \& Me. The primary objective is to teach students about the roles and challenges that engineering professions face, along with the required skill levels, knowledge and tools they must master. Imbedded in this unit is the Motivational or Student Engagement Component whereby students make connections with the Engineering profession by meeting and interviewing engineers, learning of their humanitarian projects, and coming to appreciate contributions of engineers to students' interests or tentative career choices.

The next unit, Systems Models, addresses the second objective for that year which is to understand the seminal concept used by engineers: the Engineering Algorithm. Once this thinking tool is introduced and understood, the third unit, Systems Engineering Project, is presented. The students and teacher move from the theoretical to the hands-on application. During the implementation/application phase, students will deliberately practice the work habits of engineers (i.e., teamwork protocol and the tools appropriate to their level such as data-driven decision making), to accomplish their mission.

The 10th grade units progress in a similar pattern, incorporating age/grade appropriate knowledge and skills that complement their other grade level subjects to fortify and enhance the introduction of this new discipline.

Backward Design - Educational policy debates of the last 50 years have challenged K-12 teachers to become much more focused on the psychological principles of how students learn ${ }^{11}$ and to define effective teaching through clear demonstration of student learning. One of the most effective conceptual models supporting such an approach that emerged is that of "backward design” to guide curriculum development. Backward Design as laid out by ${ }^{12}$ involves three stages:

Stage 1) identification of desired results in terms of established goals or standards, what essential questions will be considered, what understandings are desired on the part of students, 
and what key knowledge and skills students will acquire as a result of a particular unit or module;

Stage 2) determination of acceptable evidence, including performance tasks and other evidence (tests, quizzes, prompts, work samples, observations) that will show that students understand, as well as student self-assessments and reflections about their learning; and

Stage 3) planned learning experiences, the sequence of teaching and learning experiences that will equip students to engage with, develop, and demonstrate the desired understandings.

The ICE-HS Framework was developed using these steps in a workshop led by the authors. The workshop resulted in a curriculum with vision, mission, mission goals, measureable objectives and four-year engineering framework customized for the Da Vinci high school. The sequence of four engineering courses shown in Figure 1 was designed based on the workshop results.

\section{Four Year Engineering Curriculum}

\section{9th Grade}

Introduction to engineering process and disciplines

This course introduces engineering concepts and methodologies using a systems point of view, explores the impact of engineering on society and the environment, and introduces students to the roles, functions and connections of the engineering professions

Unit 1: Engineering and $\mathrm{Me}$

Unit 2: Systems Models

Unit 3: Systems Engineering Project

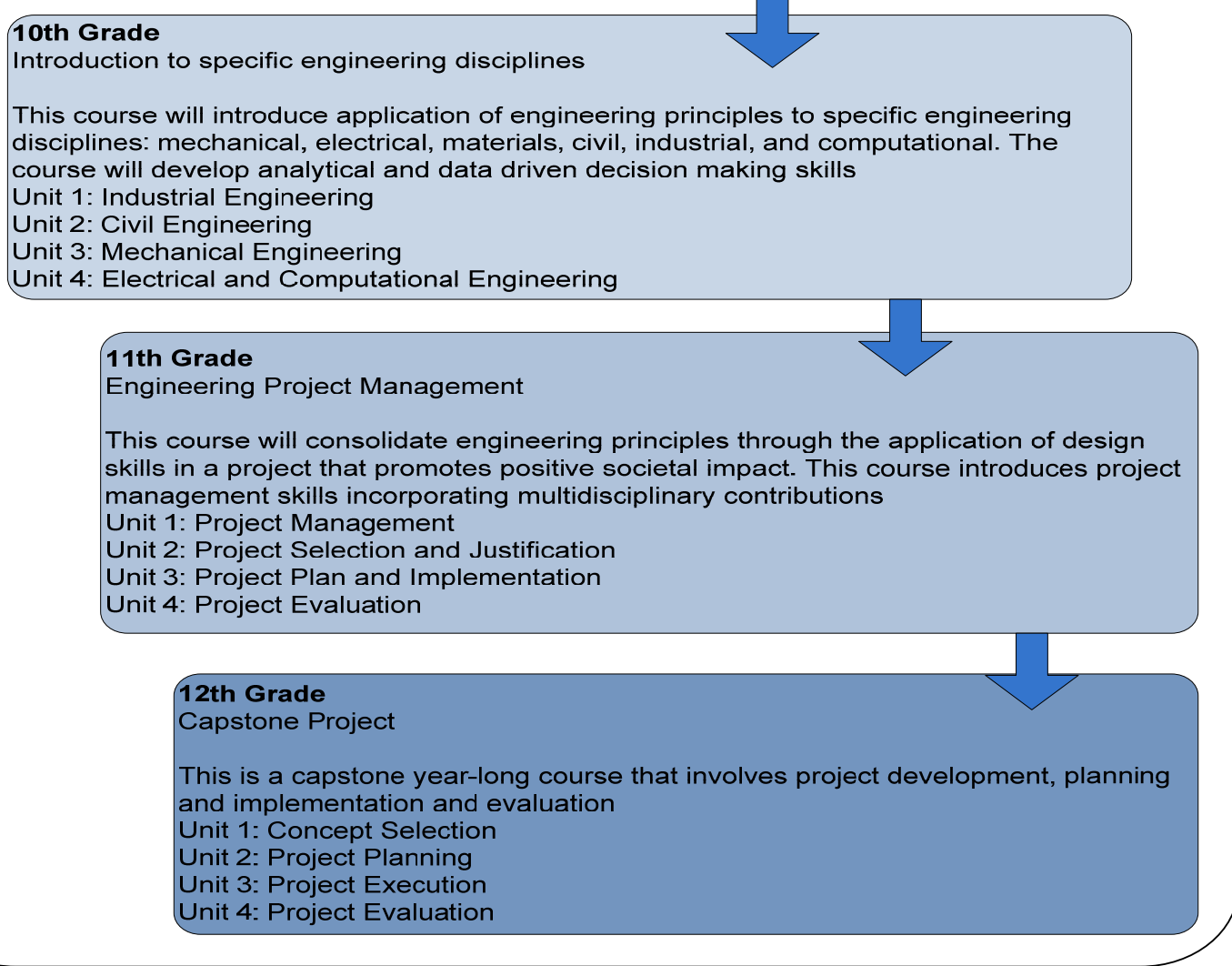

Figure 1.Four-year High School Engineering Curriculum 
The courses $9^{\text {th }}$ and $10^{\text {th }}$ grade were implemented last year and the teachers provided their syllabus as shown in following tables

Table 1: $9^{\text {th }}$ grade Syllabus for the Da Vinci Engineering Course

\begin{tabular}{|l|l|}
\hline Week & Course work \\
\hline $1^{\text {st }}$ Six Weeks & $\begin{array}{l}\text { Interest Inventory, to connect to student interests } \\
\text { Guest speakers } \\
\text { Tours/field trips } \\
\text { Videos: How it's Made, Engineering an Empire } \\
\text { Hands on challenges: Egg drop/Mars Lander, Pre- packaged kit materials }\end{array}$ \\
\hline $2^{\text {nd }}$ Six Weeks & $\begin{array}{l}\text { Engineering algorithm: } \\
\text { Practice problems and mock projects } \\
\text { Six step process } \\
\text { Problem definition } \\
\text { Research } \\
\text { Brainstorm solutions } \\
\text { Selection by data driven decision making and constraints } \\
\text { Implementation and evaluation } \\
\text { Revision and iteration if needed }\end{array}$ \\
\hline $3^{\text {rd }}$ Six Weeks & $\begin{array}{l}\text { Futuristic Class Room Design } \\
\text { Student teams conduct group work and whole group exercises to lead up to } \\
\text { power point presentation of the design of the perfect classroom of the future. } \\
\text { Apply algorithm to the problem and design }\end{array}$ \\
\hline $4^{\text {th }}$ Six Weeks & $\begin{array}{l}\text { Biodegradable unit using kit-NSF funded Material Worlds Module } \\
\text { Design of medicine delivery device, per kit student guide booklet. } \\
\text { Research and reports }\end{array}$ \\
\hline $5^{\text {th }}$ Six Weeks & $\begin{array}{l}\text { Sports materials unit using kit - NSF funded Material Worlds Module } \\
\text { Design project of improving a game }\end{array}$ \\
\hline
\end{tabular}

Table 2: $10^{\text {th }}$ grade Syllabus for the Da Vinci Engineering Course

\begin{tabular}{|c|c|}
\hline Week & Course work \\
\hline $1^{\text {st }}$ Six Weeks & $\begin{array}{l}\text { - Intro to Engineering } \\
\qquad \text { Informal survey of Engineering and show videos, } \\
\text { pictures, stories, etc, that will motivate students to learn } \\
\text { about Engineering } \\
\text { - Review of to Engineering Process } \\
-\quad \text { Step- by- step explanation of process } \\
» \text { Identify Problem } \\
» \text { Research } \\
» \text { Develop Solutions } \\
» \text { Construct Prototype } \\
» \text { Evaluate Solution } \\
» \text { Redesign if needed }\end{array}$ \\
\hline
\end{tabular}




\begin{tabular}{|c|c|}
\hline & 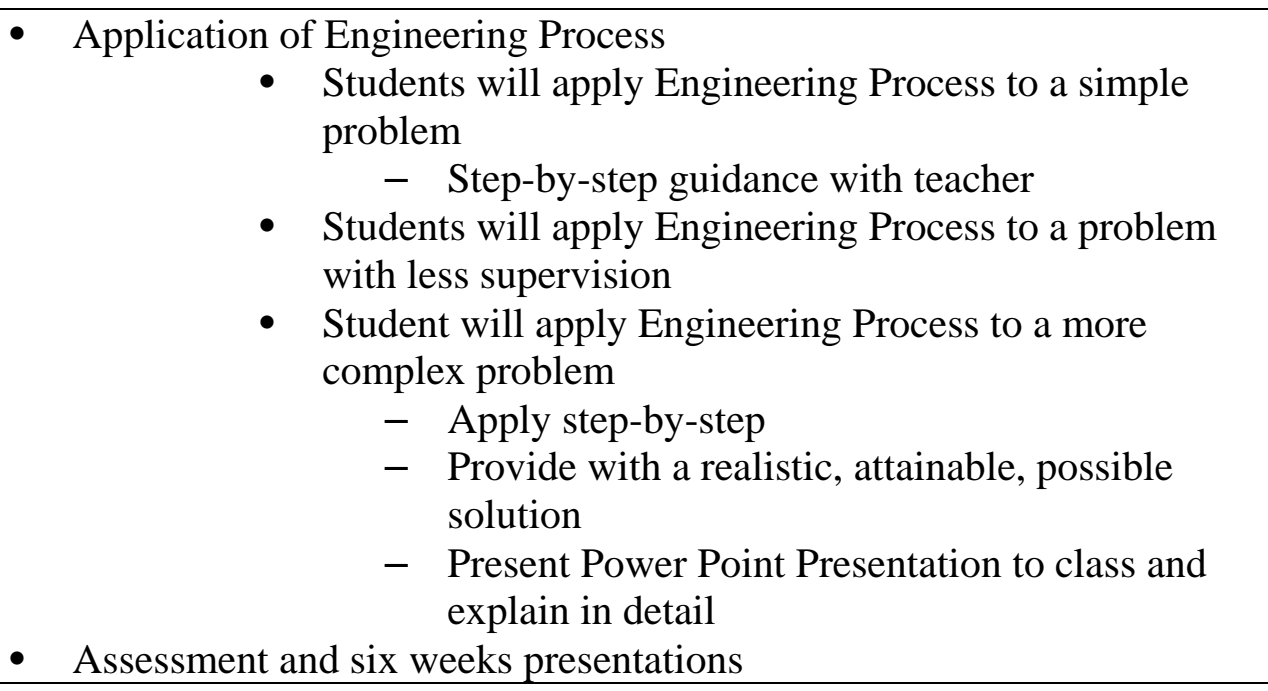 \\
\hline $\begin{array}{l}2^{\text {nd }} \text { Six } \\
\text { Weeks }\end{array}$ & 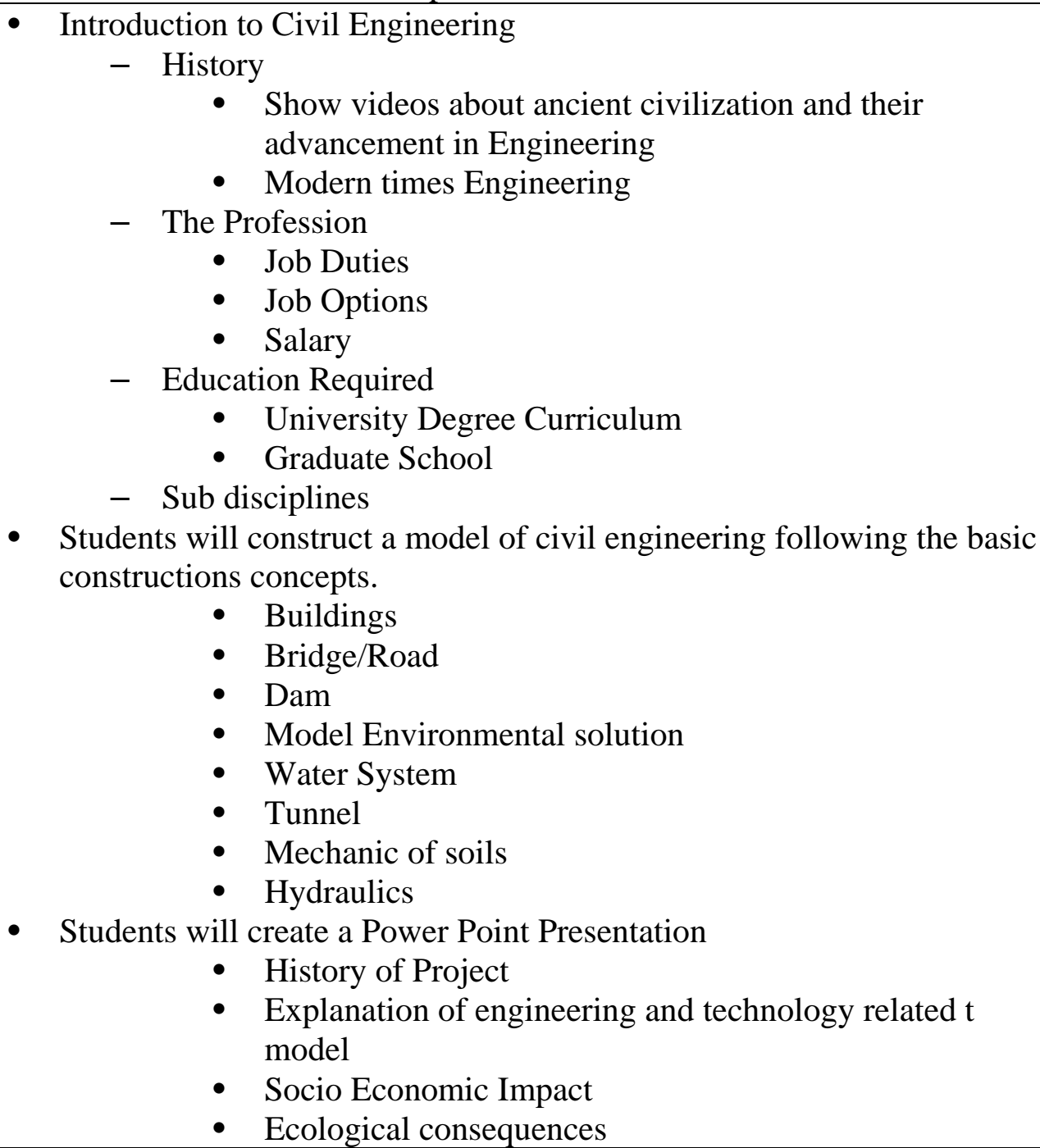 \\
\hline $3^{\text {rd }}$ Six Weeks & $\begin{array}{l}\text { - Introduction to Mechanical Engineering } \\
-\quad \text { History } \\
\bullet \quad \text { Show videos about ancient civilization and their }\end{array}$ \\
\hline
\end{tabular}




\begin{tabular}{|c|c|}
\hline & 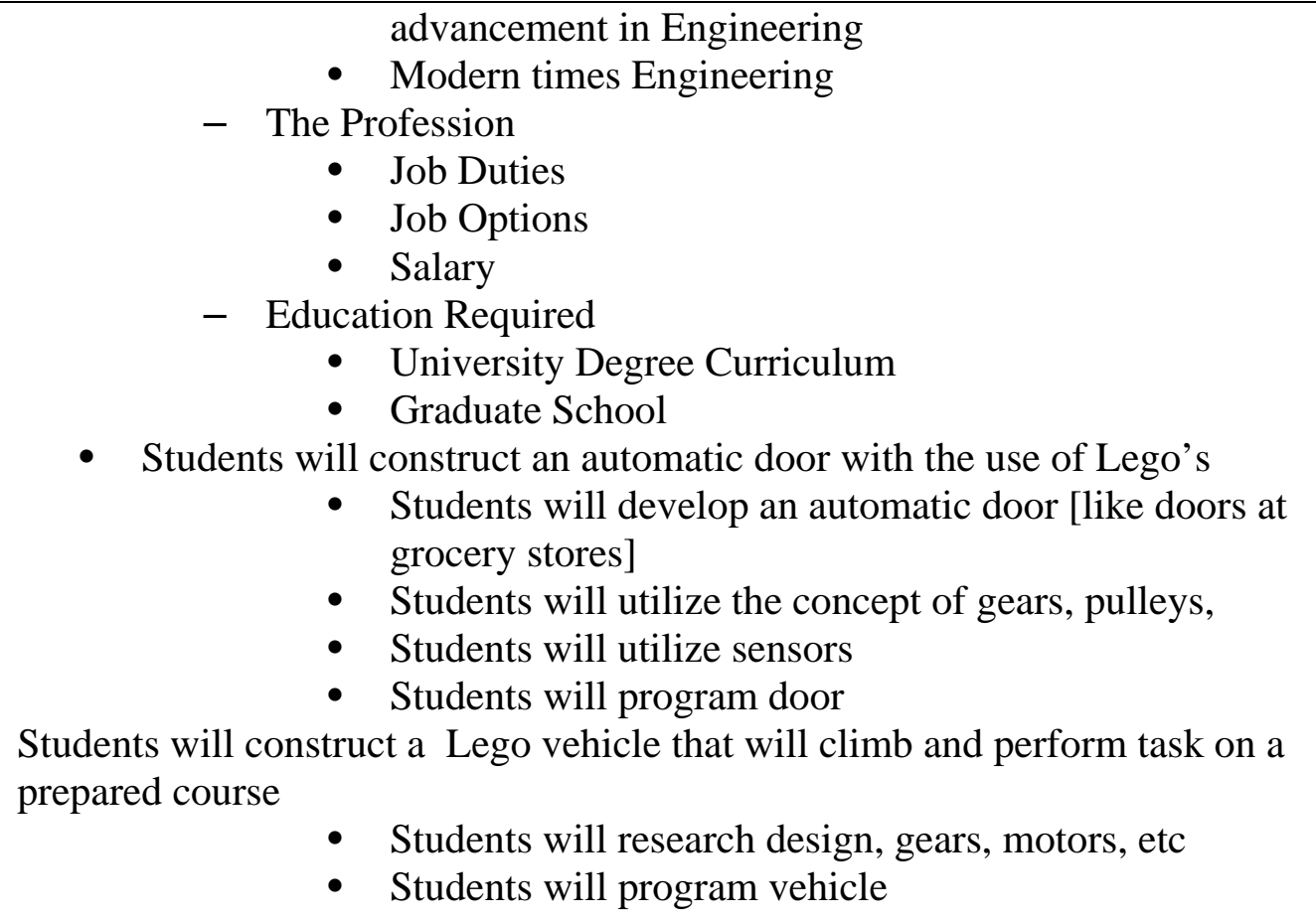 \\
\hline $4^{\text {th }}$ Six Weeks & 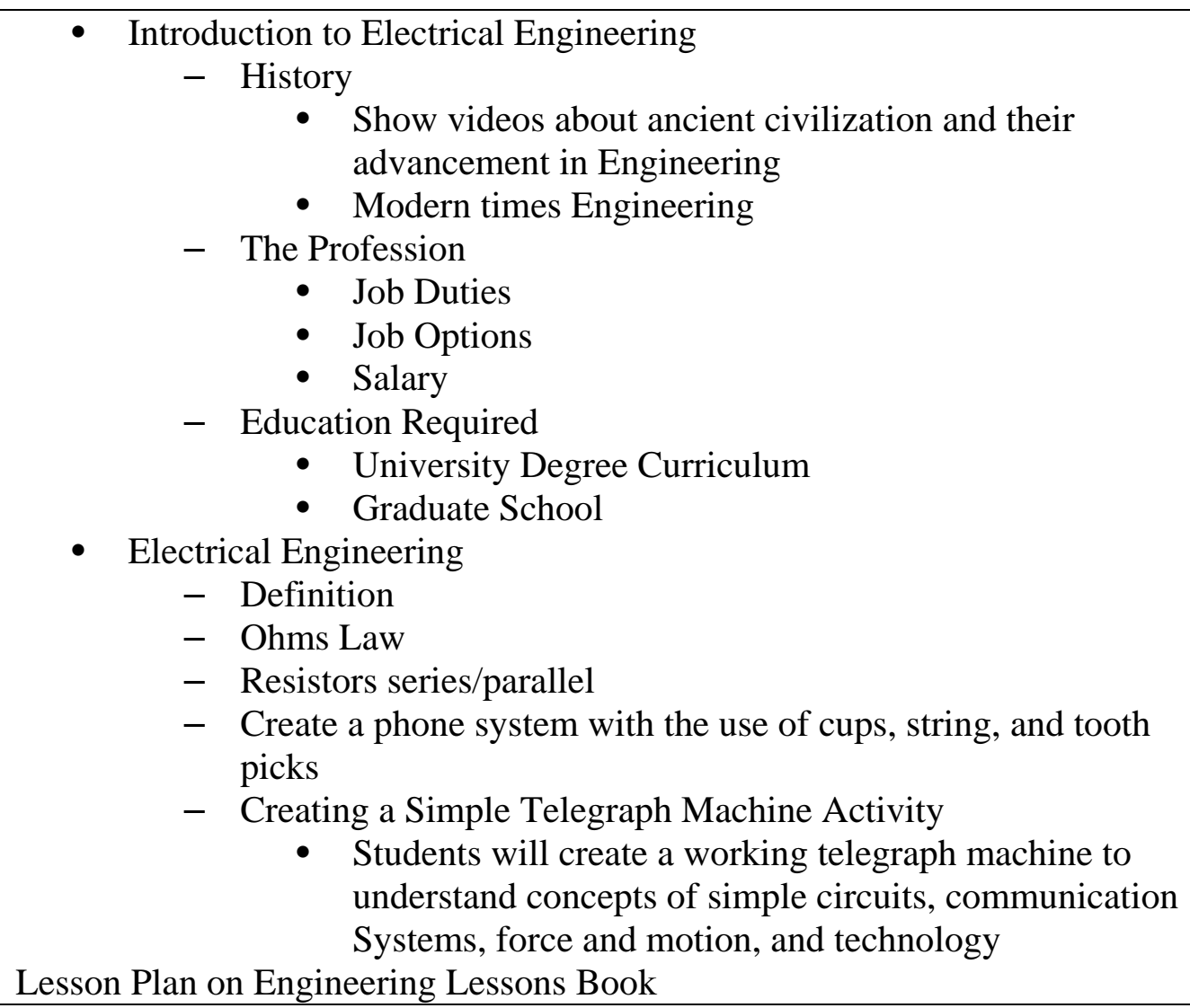 \\
\hline $5^{\text {th }}$ Six Weeks & $\begin{aligned} & \text { Computer use in Engineering } \\
& \bullet \text { Electronic Communication } \\
& \bullet \text { Word Processing } \\
&\end{aligned}$ \\
\hline
\end{tabular}




\begin{tabular}{|c|c|}
\hline & $\begin{array}{l}\text { - } \text { Spreadsheet Programs } \\
\text { - } \text { Data Base Management } \\
\text { - Computer Aided Design CAD } \\
\text { - } \text { Binary Representation } \\
\text { - Addition of Binary Numbers } \\
\text { - Micro Computers } \\
\text { - Nanotechnology } \\
\text { - Computer Programming and Software }\end{array}$ \\
\hline $6^{\text {th }}$ Six weeks & Material Worlds Module on Concrete \\
\hline
\end{tabular}

Each of these units was associated to an assessment structure. The teachers also used Edmodo.com to develop and share lesson plans that each could use in their classes. These syllabi were developed by following the ICE-HS framework. The following section gives a brief overview of ICE-HS

\section{The Innovative Curriculum for Engineering in High School (ICE-HS)}

ICE-HS framework was developed with three major dimensions: Teacher Development, Curriculum Development and Student Learning. The goals associated with each are:

1) Teacher Development: Enhance the ability of teachers to teach engineering in high school selecting, adapting and integrating grade-appropriate activities and materials from readily available, quality, research-based engineering, STEM instructional resources such as International Technology and Engineering Educators Association (ITEEA)

2) Framework Implementation: Develop a framework implementation process that can be replicated in geographically, economically and ethnically diverse high schools.

3) Student Learning: Students will come to understand increasingly complex content and concepts by learning, practicing and applying engineering design, thinking and skills.

The three goals of the research are achieved through a three-year incremental deployment coordinated with the formative assessments. The ICE-HS framework, shown in figure 2, illustrates the major activities and the outcomes for each dimension. This framework is a process based model. The replications of such models are successful when there is a buy-in from the administration and the teachers towards the STEM program. The replication methodology for ICE-HS begin by doing the framework activities as shown in figure 2 with the new high school and generate the customized four year curriculum. The authors will then develop a support mechanism to help with the implementation of the curriculum through the teacher development and phased implementation process. 


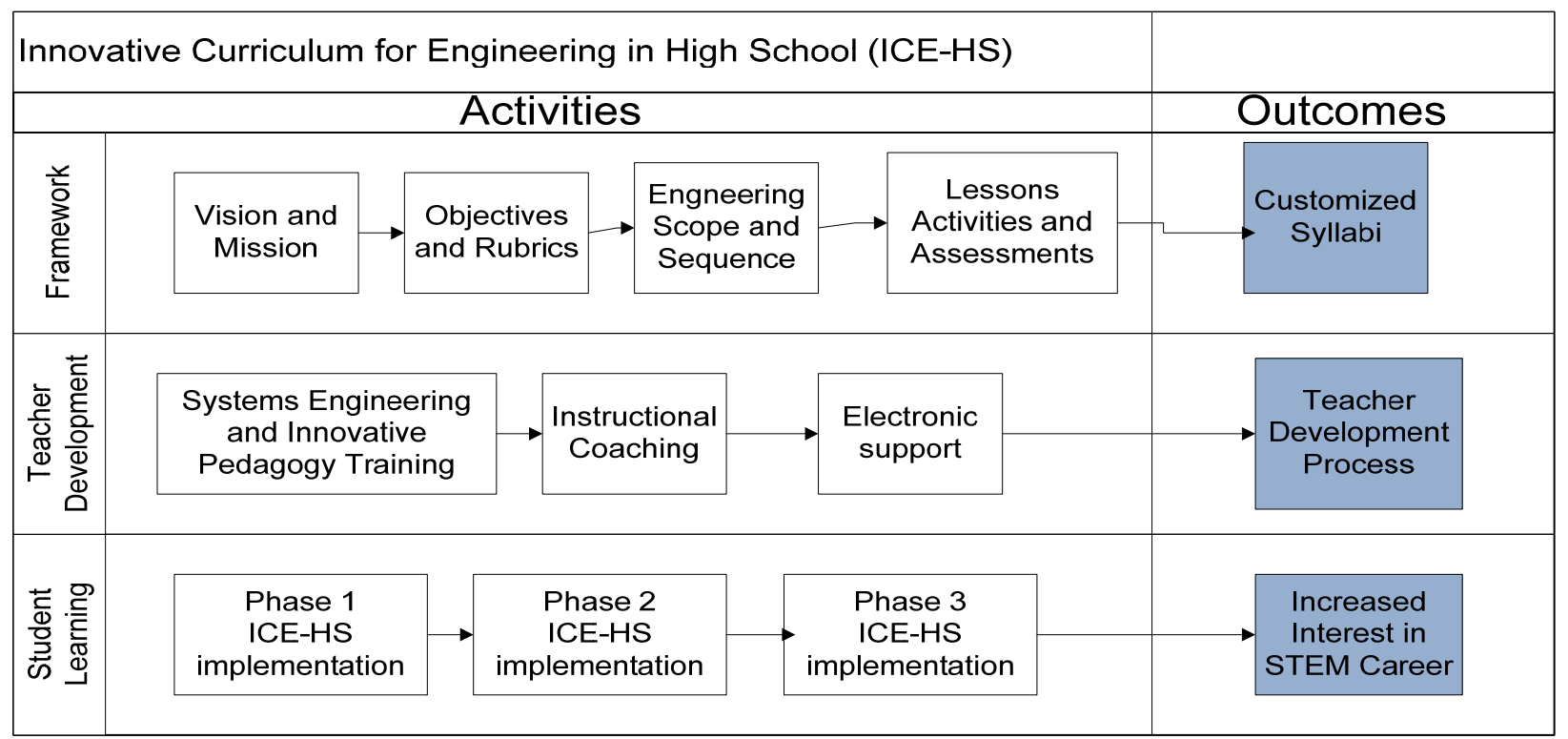

Figure 2: ICE-HS framework

\section{Evaluation}

The students of Da Vinci were given a survey developed and web administered by an external evaluator after experiencing the first implementation of the $10^{\text {th }}$ grade engineering course. The survey was an adapted version of the Student Assessment of their Learning Gains (SALG) instrument, which was developed and standardized in earlier projects sponsored by the National Science Foundation.

Content - The survey consisted of three parts: (1) Knowledge, i.e., a student's assessment of his/her understanding of major topics identified by the teacher for exploration in the class; (2) Skills, i.e., a student's assessment of his/her skills relating to the topics explored in the class; and (3) Engineering Careers, i.e., a student's interest and future plans with respect to Engineering and other STEM fields. The following text synthesizes major findings for all courses to date.

Response Rate - There were 27 students in the course, but three had left for summer vacation prior to administration of the survey. Therefore, $89 \%$ of the class participated in the pilot, with 24 students who began the survey. One student, however, only responded to the first two questions. Since 23 students completed the entire survey, the actual response rate was $85 \%$ of the class.

\section{A. Understanding of Engineering and its Core Disciplines}

At least half or more of the students indicated that they understood (by their "Yes Definitely" or "Yes" responses) the following topics: (a) the Engineering Design Process (71\%); and (b) how ideas explored in the class relate to ideas encountered in other classes outside of Engineering (52\%).

In contrast, 44 percent responded that they understood Mechanical Engineering, and less than 30 percent indicated that they understood the other disciplines: Civil Engineering (29\%); Electrical Engineering (26\%); Bioengineering (22\%); and Industrial \& Manufacturing Engineering (13\%). Only one fourth (26\%) responded that they understood the relationships among the five core Engineering disciplines, and 22 percent indicated that they understood how studying Engineering helps people address real world issues. 


\section{B. Skills}

The four areas of skill identified as strongest (responding "Yes Definitely" or "Yes") by most students included: (a) working effectively with others (78\%); (b) applying the Engineering Design Process to solve problems (61\%); (c) identifying patterns in data (61\%); and (d) prepare and give oral presentations (59\%).

The skills identified as strongest by less than half of the students were: (a) write documents in appropriate style and format for Engineering (26\%); (b) describe the characteristics of the different Engineering disciplines (35\%); (c) develop a logical argument (44\%); and (d) recognize a sound argument and appropriate use of evidence (48\%).

\section{Plans for College}

Almost 55 percent indicated that "Yes Definitely" or "Perhaps," they did intend to study Science, while 46 percent responded similarly about Math. Only 19 percent indicated that plan for Engineering, but 38 percent responded that they were "Undecided" about studying Engineering. Slightly more than one fourth (27\%) responded that "Yes Definitely" or "Perhaps" they would major in Technology, while 32 percent indicated they were "Undecided" about that field.

\section{Conclusion and Future Plans}

Preliminary data suggests an overall positive impact of ICE-HS on students of the $10^{\text {th }}$ grade. The future plans include collecting a pre and post survey for $9^{\text {th }}$ and $10^{\text {th }}$ grade students to establish a baseline and track the improvement make changes to the course and be sensitive to the changes in student attitudes towards STEM, especially engineering.

There are three more schools in Texas that have shown interest in implementing ICE-HS. The Authors plan on developing summer workshop and expand data collection across the schools to increase their sample space and impact on pre-college engineering education

\section{Reference}

1. The Oregonian "http://www.oregonlive.com/hillsboro/index.ssf/2011/12/intel_survey_of_teenagers_show.html” Accessed 01/2012

2. The Venture Beat "http://venturebeat.com/2011/12/06/teens-and-engineering/” Accessed 01/2012

3. American electronics Association, Business Roundtable, Business-Higher Education Forum, et al. (2005). Tapping America’s potential: The Education for Innovation Initiative. http://businessroundtable.org/studiesand-reports/tapping-americas-potential/

4. National Science Board. (2007). Moving forward to improve engineering education. http://www.nsf.gov/pubs/2007/nsb07122/index.jsp

5. National Academies Committee on Science, Engineering, and Public Policy. (2009). Rising above the gathering storm two years later. Washington, D.C.: National Academies Press. http://www.nap.edu/catalog/12537.html

6. Nathan, M. J., Tran, N. A., Atwood, A. K., Prevost, A., \& Phelps, L. A. (2010). Beliefs and expectations about engineering preparation exhibited by high school STEM teachers. Journal of Engineering Education, 99(4):409426.

7. Kaethi, L., Pearson, G., Feder, M., (2009). Engineering in K-12 education: Understanding the status and improving the prospects. National Academy of Engineering and National Research Council Committee on K-12 Engineering Education. http://www.nap.edu/catalog.php?record_id=12635

8. Federal Aviation Agency (USA FAA) Systems Engineering Manual, definition contributed by Simon Ramo

9. Eisner, Howard, Essentials of Project and Systems Engineering Management

10. INCOSE, Systems Engineering Handbook, version 2a, June, 2004, page 11

11. Lambert, Nadine M.(Ed);McCombs, Barbara L.(Ed) (1998).How students learn: Reforming schools through learner-centered education.Washington, DC, US: American Psychological Association. (1998). xiv 540 pp 
12. Wiggins, G. \& McTighe, J. (2005, 2nd ed.). Understanding by design. Alexandria, VA: Association for Supervision and Curriculum Development.

\section{Appendix}

\section{Da Vinci Engineering Curriculum}

\section{Vision}

Da Vinci Engineering Program will teach all students the power of integrating engineering into everyday learning

\section{Mission}

To prepare each student to design the future

\section{Mission Related Goals}

M.G.1. Accomplish broad understanding of engineering disciplines and concepts

M.G.2. Overcome misconceptions of engineering stereotypes and develop data driven decision making skill set

M.G.3. Successfully enroll in STEM field

M.G.4. Develop Autonomy in different engineering fields ...

M.G.5. Use their learning to impact the community and their own lives

Priority Based Measurable Objectives

\begin{tabular}{|l|l|r|}
\hline Objective \# & Description & Priority \\
\hline E.2. & Data driven decision making & 1 \\
\hline E.8. & Embed STEM skills in each subject & 2 \\
\hline E.1. & Engineering tools and templates & 3 \\
\hline E.7. & Community Impact & 4 \\
\hline E.3. & Project/Problem based learning & 5 \\
\hline E.4. & Team based learning & 6 \\
\hline E.6. & Effective Communication & 7 \\
\hline E.5. & Ethics & 8 \\
\hline
\end{tabular}

The Guiding Essential Question

\section{"How do I design my future? (My future / The future)" With the power of engineering}

\section{The Course Template}

Each course template should consist of the following elements

- Course Title/Name 
- Curriculum Connections

- Course Credit Hours

- Prerequisites, Co-requisite

- Grade Level (s)

- Developed by

- Instructor Name

- Course Description/ Outline

- Course Goals / Learning Outcomes

- Course Objectives and Assessments

o Unit 1

o Unit 2

0 -....

o Unit $\mathrm{n}$

- Mission Related Goals

- Instructional Materials (Resources)

- Recommended Instructional strategies (Methods of Instruction)

- Rubrics

- Suggested Real life/ Community/ Design Experience

- Total Hours of Instruction

\section{Sequence of Engineering Courses}

$9^{\text {th }}$ Grade: Eng\#1: Engineering Principles: Introduction to engineering process and disciplines $10^{\text {th }}$ Grade: Eng\#2: Technology Systems: Introduction to specific engineering disciplines $11^{\text {th }}$ Grade: Eng\#3: Problems and Solutions in Technology: Engineering Project Management $12^{\text {th }}$ Grade: Eng\#4: Research Design and Development: Synthesis 